\title{
Prevalence and Risk Factors of Vaginal infection among women in Reproductive age group at Hassan Shami Camp
}

\author{
DUAA EDREES THANNOON ALDULAIMY ${ }^{1}$, SALWA HAZIM ALMUKHTAR ${ }^{2}$ \\ ${ }^{1}$ M.SC. MCHN. College of Nursing, University of Mosul, City of Mosul, Iraq \\ ${ }^{2}$ Professor, PhD. MCHN, College of Nursing, University of Mosul, City of Mosul, Iraq \\ *Correspondence to Dr. Salwa Hzim Al Mukhtar, Email: dr.salwa@uomosul.edu.iq.
}

\begin{abstract}
During the reproductive age, it may be for women. Some diseases can be transmitted through a sexual partner or a disturbance in the normal flora of the vagina, as in vaginal infection. The Objectives of the study were to determine the prevalence and types of vaginal infections, also to explore the related risk factors of vaginal infection among women in the reproductive age Group at Hassan-Sham Camp, and find out the relationship between a sociodemographic characteristic and vaginal infection. Cross-sectional descriptive study for 145 women, visiting primary health care centers at Hassan Shami camp from a period (6th December 2020 to 25 th February 2021) by obtaining vaginal swab and investigating it, for verify the types of vaginitis. The finding indicates the prevalence of bacterial vaginal infection (29.7\%), mixed Bacteria and candida (26.9\%), fungal infection(candida)(25.5\%), mixed(candida and parasite)(1.4\%), and(16.6\%) normal flora, and the study illustrates the correlation between the sociodemographic data and vaginal infection was nonsignificant. The study showed the water used for daily practices has a crucial role in causing bacterial vaginal infection, also showed a significant effect between obstetrical data, Sexuality data (except U.T.I. for husband), lifestyle data except(smoking), genital area care practices, medical history except(anemia), signs and symptoms of vaginitis and vaginal infection. Necessary to open laboratories in PHCC of the camp and open special sections for nursing education to raise health awareness among women, providing the displaced a suitable living environment.

Keywords: vaginal infection, risk factors, Hassan Shami camp
\end{abstract}

\section{INTRODUCTION}

The World Health Organization (WHO) has estimated that over 340 million new sexually transmitted infections occur each year, with $75-85 \%$ of them observed in developing countries $^{(1-3)}$. The gynecological disease is a significant threat to women's reproductive health. Effective measures should be taken to address the issue, especially to women of childbearing age ${ }^{(4)}$. Vaginitis is the most common infectious disease of the female genital tract during childbearing age. Common vaginal infections mainly include B.V. (Bacterial Vaginosis), A.V. (Aerobic Vaginitis), V.V.C. (Vulvovaginal Candidiasis), and T.V. (Trichomoniasis). Mixed vaginitis refers to the infection of two or more pathogens in the vagina at the same time. Commonly mixed vaginitis mainly includes $B V+V V C$, $B V+A V, A V+V V C, T V+A V, T V+B V, T V+V V C$, etc. (li et al., 2021). The interaction between fungi and bacteria can mutually promote the colonization and virulence of pathogens ${ }^{(5,6)}$. Low income, low education level, previous vaginal infections, poor personal hygiene, history of antibiotic use, and external hemorrhoids are known risk factors for B.V., V.V.C., and A.V. during pregnancy, but no studies have analyzed the risk factors of pregnant women with mixed vaginitis ${ }^{(7,8)}$. It is the crucial reason for women to visit their doctors. It is difficult to determine the actual occurrence of vaginal infections. The doctors use the word vaginitis as a synonym for infections, believing that all vulvovaginal irritations or itching, especially when accompanied by irregular secretions, are caused by microorganisms ${ }^{(9)}$. The environment of the vagina is profoundly affected by the level of the hormone oestradiol $(10,11)$. Several sociodemographic factors have been associated with reproductive tract infections, such as parity, poor socio-economic conditions, poor menstrual hygiene, and illiteracy, the diagnosis without laboratory confirmation can lead to inappropriate medication ${ }^{(12)}$ Bacterial vaginosis is the most common cause of vaginal discharge among females of reproductive age. ${ }^{(13)}$ vaginal discharge (thin and white, with musty or fishy odor) is the most frequent symptom in women of reproductive age ${ }^{(14)}$. The prevalence rate is about 21.2 million (29.2\%) worldwide ${ }^{(15)}$. The general population prevalence of B.V. is high globally, ranging from $23 \%$ to $29 \%$ across regions (Europe and Central Asia, 23\%; East Asia and Pacific, 24\%; Latin America and Caribbean, 24\%; the Middle East and North Africa, 25\%; sub-Saharan Africa, 25\%; North America, 27\%; South Asia, 29\% $)^{(16)}$.Multiple risk factors including vaginal douching, low socio-economic status, cigarette smoking, antibiotic treatment for another condition, young age of coitarche, (17). It has been associated with indicators of high-risk sexual behavior such as a new sexual partner or a more significant number of male partners within the last year, an increased number of lifetime sexual partners ${ }^{(18)}$. The study of prevalence and risk factors of vaginal infection among women in reproductive age group at Hassan Shami camp.

\section{METHODOLOGY}

A cross-sectional descriptive study design was employed to achieve the study aims. This study was performed between 6th December 2020 to 25th February 2021 in two primary health care centers at Hassan Shame camps related to the Hamdani sector of the Nineveh department of health, Iraq.This study was performed between the period of 6th December 2020 to 25th February 2021 in two primary health care centers at Hassan Shami camps related to the Hamdania sector of Nineveh Governorate, Iraq.The study was done at two PHCCs at Hassan Shami camp. They belong to the Hamdania sector of the Nineveh department of health, Iraq.Both located in Hassan Shami village, which 
is $35 \mathrm{~km}$ east of Mosul, on the banks of the Khazar River in Iraq, the PHCCs was built and opened by The United Nations High Commissioner, responding to the expected large-scale displacement from Mosul, it is elementary PHCC it contains a Management room, doctor room, the pharmacy and finally the Nursing room which is a tiny room with simple equipment. The samples were selected purposively. The study contained 145 women of reproductive age group (based on epi info application for determining the sample size). These women visited the camp's primary health care centers to find treatment for their urgent health problem (vaginitis). We used sterile disposable speculums and swabs that contain transporter media that have a Nourishing medium for the microorganisms; it preserves the integrity of the sample from damage till reaching the laboratory Because the PHCCs of camp do not contain a laboratory. Obtain a vaginal swab sample from each woman of the reproductive age group diagnosed with vaginitis. Informed consent was taken, and researchers within the face filled the information sheet to face interview of each participant in the study. Gather data from women attending primary health care centers at camp. The data collection form is one of the essential tools used in research. It is the best way for researchers to obtain information and data applicable to the study concept. It is often used to identify the direction of the study population and explore their behavior and discover crucial information that can help the researcher perform scientific research successfully.A pretest semi-structured questionnaire based on face-to-face interview was used to obtain data about characteristics of the participants, such as age, marital status level of education, obstetric history, Education level, B.M.I., Sexuality Data, nutritional habits, and Lifestyle, genital care habits, History of diabetes, using antibiotics and steroids a lot and finally the signs and symptoms. After data collection, the data encoded, organized, and introduced Into a computer file. Statistical package for social science (SPSS) version 26 Was used for data analysis. The results presented significance if the $p$-value $\leq 0.05$. and non-significance when it is $>0.05$

\section{RESULTS}

The table (1) explains the obstetrical data of vaginal infected women, where showed most cases were (4-6) gravidity Sig 0.000 and 4-6 parity Sig 0.000 , while most of them have no abortion Sig 0.000 , according to Pregnancy Status Sig 0.000 , the most cases were nonpregnant, none trimester, most of cases the number of premature deliveries was(none) Sig 0.000 , the menstrual status of non-pregnant infected women was irregular in the most cases Sig 0.000, and almost of them were did not use contraceptives Sig 0.000 . The table(2) explains the sexuality data of infected women, where the most infected women were have no sexual intercourse Sig 0.001 , the second ratio showed in women who practicing the sexual intercourse for(1OR 2 times /week), the age of women at first sexual intercourse was less than 18 years old Sig 0.025 , higher ratio was in women who her husband was not has multiple wives Sig 0.000 , and with no sexual transmitted diseases Sig 0.000, and reproductive diseases Sig 0.000 , but the husbands of infected women who have urinary tract infection were presented the most cases Sig 0.914.

Table (1: A): vaginal infection factors among Women according to obstetrical data.

\begin{tabular}{|c|c|c|}
\hline \multicolumn{3}{|c|}{ Gravidity } \\
\hline$\%$ & $f$ & \\
\hline 4.8 & 7 & None \\
\hline 24.1 & 35 & $1-3$ \\
\hline 40.7 & 59 & $4-6$ \\
\hline 30.3 & 44 & 7and more \\
\hline 100 & 145 & Total \\
\hline Df 4 & Sig 0.000 & Chi-Square81.724 \\
\hline \multicolumn{3}{|c|}{ Parity } \\
\hline$\%$ & $f$ & \\
\hline 6.9 & 10 & None \\
\hline 31.0 & 45 & $1-3$ \\
\hline 39.3 & 57 & $4-6$ \\
\hline 22.8 & 33 & 7and more \\
\hline 100 & 145 & Total \\
\hline Df 3 & Sig 0.000 & Chi-Square33.290 \\
\hline \multicolumn{3}{|c|}{ Abortion } \\
\hline$\%$ & $f$ & \\
\hline 59.3 & 86 & None \\
\hline 37.2 & 54 & $1-3$ \\
\hline 3.4 & 5 & $4-6$ \\
\hline 100 & 145 & Total \\
\hline Df 2 & Sig 0.000 & Chi-Square68.8693.503 \\
\hline \multicolumn{3}{|c|}{ Pregnancy Status } \\
\hline$\%$ & $f$ & \\
\hline 5.5 & 8 & Yes \\
\hline 91.0 & 132 & No \\
\hline 3.4 & 5 & I.D.KNOW \\
\hline 100 & 145 & Total \\
\hline Df 2 & Sig.000 & Chi-Square 217.338 \\
\hline
\end{tabular}

Table (1: B): vaginal infection factors among Women according to obstetrical data.

\begin{tabular}{|l|l|l|}
\hline Pregnancy Trimester & \\
\hline Percent & Frequency & 2nd trimester \\
\hline 3.4 & 5 & 3rd trimester \\
\hline 2.1 & 3 & None \\
\hline 94.5 & 137 & Total \\
\hline 100 & 145 & Chi-Square 244.028 \\
\hline Df 2 & Asymp. Sig .000 & \\
\hline Number of premature deliveries & \\
\hline Percent & Frequency & None \\
\hline 93.1 & 135 & $1-3$ \\
\hline 6.9 & 10 & Total \\
\hline 100 & 145 & Chi-Square 107.759 \\
\hline Df 1 & Asymp. Sig .000 & \\
\hline MC.STATUS & \multicolumn{2}{|l|}{} \\
\hline Percent & Frequency & REGULARA \\
\hline 42.8 & 62 & IRREGULAR \\
\hline 45.5 & 66 & Th.No.Mc \\
\hline 11.7 & 17 & Total \\
\hline 100 & 145 & Chi-Square30.634 \\
\hline Df 2 & Asymp. Sig 0.000 & \\
\hline Contraception TYPE & Frequency & \\
\hline Percent & \multicolumn{2}{|l|}{} \\
\hline
\end{tabular}


Table (2): Statistical Results of Vaginal Infection Factors among Women in the Reproductive Group According to Sexuality Data.

\begin{tabular}{|c|c|c|}
\hline \multicolumn{3}{|c|}{ Intercourse Times/Week } \\
\hline Percent & Frequency & \\
\hline 29.0 & 42 & 1OR 2 TIME /WEEK \\
\hline 25.5 & 37 & $3-5 / \mathrm{W}$ \\
\hline 11.7 & 17 & More than5 T/W \\
\hline 33.8 & 49 & None \\
\hline 100 & 145 & Total \\
\hline Df 3 & Asymp. Sig 0.001 & Chi-Square15.634 \\
\hline \multicolumn{3}{|c|}{ First sexual intercourse } \\
\hline Percent & Frequency & \\
\hline 59.3 & 86 & less than $18 \mathrm{Y}$ \\
\hline 40.7 & 59 & $18 \mathrm{Y}$ and above \\
\hline 100 & 145 & Total \\
\hline Df 1 & Asymp. Sig 0.025 & Chi-Square5.028 \\
\hline \multicolumn{3}{|c|}{ N. Husband wives } \\
\hline Percent & Frequency & \\
\hline 3.4 & 5 & YES \\
\hline 62.8 & 91 & NO \\
\hline 33.8 & 49 & Th.No.H \\
\hline 100 & 145 & Total \\
\hline Df 2 & Asymp. Sig 0.000 & Chi-Square76.524 \\
\hline \multicolumn{3}{|l|}{ STD } \\
\hline Percent & Frequency & \\
\hline 66.2 & 96 & NO \\
\hline 33.8 & 49 & Th.No.H \\
\hline 100 & 145 & Total \\
\hline Df 1 & Asymp. Sig 0.000 & Chi-Square 15.234 \\
\hline \multicolumn{3}{|c|}{ R.S.D for husband } \\
\hline Percent & Frequency & \\
\hline 8.3 & 12 & YES \\
\hline 57.9 & 84 & NO \\
\hline 33.8 & 49 & There is.No.Husband \\
\hline 100 & 145 & Total \\
\hline Df 2 & Asymp. Sig .000 & Chi-Square 17.269 \\
\hline \multicolumn{3}{|c|}{ U.T.I. for husband } \\
\hline Percent & Frequency & \\
\hline 34.5 & 50 & YES \\
\hline 31.7 & 46 & NO \\
\hline 33.8 & 49 & There is.No.Husband \\
\hline 100 & 145 & Total \\
\hline Df 2 & Asymp. Sig 0.914 & Chi-Square 0.179 \\
\hline
\end{tabular}

\section{DISCUSSION}

In this study, this study found the age of women who were infected with vaginal infection in reproductive age is significant at 0.001, Chi-Square18.138, Df4.where the age group who has the higher percentage among infected women was (29-35) y $31.0 \%$, then (36-42) y $23.4 \%,(22-28)$ y $20.0 \%$, (15-21) y $15.2 \%$ and the lesser ratio founded in the group age of (43-49) y 10.3\%, the researcher's point of view is at (29-35) the vaginal infection increases due to full activity of estrogen hormone especially in puberty period or during pregnancy. These results are approximately in agreement with (Zhu et al., 2016) ${ }^{(19)}$ study who found the mean age of infected women was 0.96 and 29.75 years.The study reveals that the majority of infected women in those whose education was of primary school level $59.3 \%$, while the percentage in those of Illiteracy $29.7 \%$, then secondary level E.D.U. with a percent $10.3 \%$, On the other hand, the minority of them $0.7 \%$ were found in infected women who in high education level and the Sign
0.000 , Chi-Square116.269 and degree of freedom is 3.the researcher's point of view is whenever increasing the level of learning and knowledge leads to more prevention of disease, and vice versa, the environment of camp doesn't encourage education and almost of young female and even children don `t go to school, hence lack of health education lead to increasing prevalence of infection. These results are approximately agreement with (Mohamed, 2016)(20) study who found the Illiterate $35.0 \%$ and University or higher $15.0 \%$.Our study shows the percentage of married infected women is $66.2 \%$, while the unmarried (divorced and widow) constitute $(11.0 \%$ and $22.8 \%)$, ChiSquare73.503, Sign 0.000. Df 2.The researcher's point of view is after marriage the sexual intercourse and pregnancy status have a vital role in increasing vaginal infection. These results are approximately agreement with (Mohamed:, 2016) ${ }^{(20)}$ study who found the unmarried was represent $20.0 \%$, and the married constitutes $80 \%$.In the current study, the infected women who live in a tent were constituted $58.6 \%$, while the partial building in the tent $41.4 \%$, Chi-Square 4.310, Sig 0.038, Df 1 the researcher's point of view is the living in a worn out tent with exposure to sever weather during winter and summer and the rising the temperature inside the tent or increase the humidity at winter, All these conditions create a favorable environment for fungi and bacteria to grow. There is no previous study about effect living in tent on vaginal infection. In our study, the factor number of family members of the infected women show a relationship, where the Members of Family of the infected women is (1-3) person constitute $17.2 \%,(4-6)$ person constitute $39.3 \%$, while 7 persons and above was $43.4 \%$, the Chi-Square 17.269, Sign .000 and D.F. was 2. The researcher's point of view is, whenever the number of family members inside the tent increase, the crowded increase also the stress increase and nutrition decrease due to poverty all those situations can lead to vaginal infection.Our study shows the effect of the accomodation duration on vaginal infection, this study found that ChiSquare 67.593, Sig .000 and DF was 1, the higher percentage of infected women $84.1 \%$ were in women who live in camp since years, while $15.9 \%$ found in women live in camp since months.the researcher's point of view is, many women in the camp reported that their vaginal infections increased when they entered the camp, the poverty of health care services, economic status beside insufficient environment of camp.The current study explained the higher ratio presented in infected women who the BMI (25.0-29.9 Overweight) was 35.9\%, then (18.5-24.9 Normal) $31.7 \%$, (30.0-34.9 Obese (Class I)) 18.6\%, (35.0-39.9 (Class II))11.0\%, (40.0 and more(Class III)) $2.8 \%$, Chi-Square55.724, Sig 0.000 and Df 4.The researcher's point of view is the fungal infection is exacerbating in overweight. The results of a study are in disagreement with a study of (Ventolini et al., 2017) ${ }^{(21)}$ that found higher BMI. was associated with recurrent vulvovaginal bacterial infections in women of reproductive age, also approximately agreement with study of (Mahmoudi Rad et al., 2011) (22) who found $25 \%$ of infected women were overweight.Our study shows the infected women who get pregnant for (4-6) times was 40.7 the higher risk among infected women, and in the next rank comes the women who get pregnant for 7 times and more 
$30.3 \%$, while the women who get pregnant for 1-3 times was $24.1 \%$, the lesser ratio $4.8 \%$ was for the women who have ever become pregnant, Chi-Square81.724, Sig 0.000, Df 4 The researcher point of view is multigravida women is more likely to be infected than nulligravida due to hormonal effects. These results are approximately agreement with (Essa \& Hussein, 2018)(23) who found (\%56.6) of infected women get pregnancy for 3-5 times. This study illustrates the infected women who have parity between (4-6) is having a higher ratio of $39.3 \%$, then $31.0 \%$ for women who have parity between (1-3), parity 7 and more is $22.8 \%$, and finally the infected women who have no children get the percent 6.9\%, Chi-Square33.290, Sig 0.000, DF3.The researcher point of view is the multipara women more likely to get vaginal infection because of hormonal fluctuation due to breast feeding or due to acquired infection during labor normally or cesarian. These results are disagreement with (Rathod \& S., 2016) $)^{(23)}$ who found $(72.5 \%)$ women with vaginitis were nulliparous, $(20 \%)$ were primipara, $(5 \%)$ were second para and the remaining (2.5\%) were para three and above. The study noted that most infected women $59.3 \%$ didn`t have any abortion status, lesser percent $3.4 \%$ found in women who have abortion between 4-6 times, chiSquare68.8693.503, Sig 0.000, Df 2. The researcher point of view is the women who exposing to curettage is more likely to acquired vaginal infection.These results are disagreement with (Essa \& Hussein, 2018)(23) who found that $13.7 \%$ of infected women are having Abortion multiple times.This study reveals that majority of women with vaginal infection were higher percentage in non-pregnant women in $91.0 \%$ of them, and the rest percentage $5.5 \%$ and $3.4 \%$ among pregnant and those who have suspicious pregnancy, Chi-Square 217.338, Sig 0.000, Df 2.The researcher point of view is in pregnancy status estrogen hormone increase and lead to increase occurrence vaginal candidiasis. These results are disagreement with (Saeed et al., 2016)(24) who found the lesser ratio (21.8) of vaginal infected women were nonpregnant, while (78.2) in pregnant women.Our study found that the percentage of vaginal infection women was $94.5 \%$ in women non-pregnant, and $3.4 \%$ and $2.1 \%$ for 2 nd trimester and 3rd trimester, ChiSquare 244.028, Sig .000, DF2.The researcher point of view is decreasing immunity in the second and third trimester beside that, in our study approximately $33.8 \%$ are of unmarried women also is another causative for increasing the ratio of non-pregnant in our study.Aguin \& Sobel, 2015 study results are $90.7 \%$ of patients were in the second and third trimesters, which is in disagreement with our study.

Ethical Clearance- formal approval was getting from the Ministry of health /Nineveh health director /Department of Knowledge Management and research/ Management of primary health care center of Hassan Shame and Management of primary health care center of Hassan Shame U2 to collect the data from those primary health care centers. consent was obtained from the woman after the study was presented to them. The study's objective is the confidentiality of the study the right to withdraw.

Source of Funding- SELF

Conflict of Interest- Nil

\section{REFERENCES}

1. Mayaud P, Mabey DJSti. Approaches to the control of sexually transmitted infections in developing countries: old problems and modern challenges. 2004;80(3):174-82.

2. Krishna Ray MB, Gupta S, Khunger N, Puri P, Muralidhar S, Kumar JJIJMR. Changing trends in sexually transmitted infections at a Regional STD Centre in North India. 2006;124:559-68.

3. Memish ZA, Osoba AOJTM, Disease I. International travel and sexually transmitted diseases. 2006;4(2):86-93.

4. Macfarlane A, Greenhalgh TJBp, childbirth. Sodium valproate in pregnancy: what are the risks and should we use a shared decision-making approach? 2018;18(1):1-11.

5. Su W, Liu J, Bai P, Ma B, Liu WJBm. Pathogenic fungiinduced susceptibility is mitigated by mutual Lactobacillus plantarum in the Drosophila melanogaster model. 2019;19(1):1-12.

6. Stringlis IA, Yu K, Feussner K, De Jonge R, Van Bentum S, Van Verk MC, et al. MYB72-dependent coumarin exudation shapes root microbiome assembly to promote plant health. 2018;115(22):E5213-E22.

7. Shehata H, Lyons E, Jordan K, Raizada MJJoam. Bacterial endophytes from wild and ancient maize are able to suppress the fungal pathogen Sclerotinia homoeocarpa. 2016;120(3):756-69.

8. Rai M, Agarkar GJCRiM. Plant-fungal interactions: what triggers the fungi to switch among lifestyles? 2016;42(3):428-38

9. Paczkowska M, Chanaj-Kaczmarek J, Romaniuk-Drapała A, Rubiś B, Szymanowska D, Kobus-Cisowska J, et al. Mucoadhesive chitosan delivery system with Chelidonii herba lyophilized extract as a promising strategy for vaginitis treatment. 2020;9(4):1208.

10. Mihajlovic J, Leutner M, Hausmann B, Kohl G, Schwarz J, Röver $\mathrm{H}$, et al. Combined hormonal contraceptives are associated with minor changes in composition and diversity in gut microbiota of healthy women. 2021.

11. Bowman RE, MacLusky NJ, Sarmiento $Y$, Frankfurt $M$, Gordon M, Luine VNJE. Sexually dimorphic effects of prenatal stress on cognition, hormonal responses, and central neurotransmitters. 2004;145(8):3778-87.

12. Griesbeck M, Altfeld M. Sex differences in the manifestations of HIV-1 infection. Sex and gender differences in infection and treatments for infectious diseases: Springer; 2015. p. 103-81.

13. Donders GG, Ruban K, Bellen G, Grinceviciene SJEoop. Pharmacotherapy for the treatment of vaginal atrophy. 2019;20(7):821-35.

14. Garza J, Gandhi K, Choi S, Sanchez A, Ventolini GJWsH. Cytokine profiles and Lactobacillus species presence in premenopausal subjects with genital Mycoplasma genitalium or Ureaplasma urealyticum colonization. 2021;17:17455065211009181.

15. Meng Y, Lv P-P, Ding G-L, Yu T-T, Liu Y, Shen Y, et al. High maternal serum estradiol levels induce dyslipidemia in human newborns via a hepatic HMGCR estrogen response element. 2015;5(1):1-11.

16. Bau D, Zhu J-Y, Wulff J, Peebles W, Strobelt H, Zhou B, et al., editors. Seeing what a gan cannot generate. Proceedings of the IEEE/CVF International Conference on Computer Vision; 2019.

17. Sarin S, Kumar M, Lau G, Abbas Z, Chan H, Chen C, et al. Asian-Pacific clinical practice guidelines on the management of hepatitis B: a 2015 update. 2016;10(1):1-98.

18. Galyfos GC, Geropapas GE, Sianou A, Sigala F, Filis KJJovs. Risk factors for postoperative delirium in patients undergoing vascular surgery. 2017;66(3):937-46.

19. Zhu L, Lu Z, Zhu L, Ouyang X, Yang Y, Feng Y, et al. Plasma lipoprotein (a) levels are associated with the severity of coronary heart disease in Han Chinese people. 
2016;46(4):1033-41.

20. Mohamed-Ahmed O, Hinshaw K, Knight MJBP, Obstetrics RC, Gynaecology. Operative vaginal delivery and postpartum infection. 2019;56:93-106.

21. Ventolini G, Khandelwal N, Hutton K, Lugo J, Gygax SE, Schlabritz-Loutsevitch NJPmj. Obesity and recurrent vulvovaginal bacterial infections in women of reproductive age. 2017;93(1099):297-

22. Rad MM, Zafarghandi S, Abbasabadi B, Tavallaee MJEJoO,
Gynecology, Biology R. The epidemiology of Candida species associated with vulvovaginal candidiasis in an Iranian patient population. 2011;155(2):199-203.

23. Alsamarai AM, Khorshed SAJI. Risk Factors in Diabetes and Pregnant Women with Urinary Tract Infections Compared to Younger Aged Female. 2018;1(3).

24. Syed labal S. A Clinical study on the dermatological manifestations of obesity: Coimbatore Medical College, Coimbatore; 2016. 